\title{
Pentingnya Inovasi Produk dan Desain Produk Terhadap Keputusan Pembelian Berulang Pada Brand Iphone di Indonesia
}

Submitted Date:

22 Maret 2021

Accepted Date:

13 Juli 2021
Sofi Kurnia Sari

Universitas Singaperbangsa Karawang sofi.kurnia17211@student.unsika.ac.id

Anggia Novanda Isrofani*

anggianovanda@gmail.com

Universitas Singaperbangsa Karawang

Citra Pratiwi

Universitas Singaperbangsa Karawang

Reminta Lumban Batu

Universitas Singaperbangsa Karawang

\section{Abstract:}

This research aims to explain the effect of the product innovation variables and product design partially on the repeated purchase decisions of an iPhone smartphone. This study uses 3 variables; namely product innovation (X1), product design $(X 2)$, and repeat purchase decisions (Y). Data collection was obtained by distributing questionnaires to the iPhone user community in Indonesia. The sample used in this study amounted to 100 respondents. Analysis of the data used is descriptive analysis, verification, normality test, and regression analysis. The sampling technique of this study was Stratified Random Sampling using the Slovin formula. The type of data used in this study is primary data and secondary data. The results of this study prove that Product Innovation and Product Design have a positive and significant effect on Repeated Purchasing Decisions.

Keywords: Iphone Indonesia, Product Design, Product Innovation, Repeated Purchasing Decisions,

Abstrak

Penelitian ini bertujuan untuk menjelaskan pengaruh variabel inovasi produk dan desain produk terhadap keputsan pembelian berulang pada brand iphone. Penelitian ini menggunakan 3 variabel; yaitu inovasi produk (X1), desain produk (X2) dan keputusan pembelian berulang $(Y)$. Pengumpulan data diperoleh melalui penyebaran kuesioner kepada komunitas pengguna iphone di Indonesia. Sampel yang digunakan dalam penelitian ini berjumlah 100 orang responden. Analisis data yang digunakan adalah analisis deskriptif, verifikatif, uji normalitas dan analisis regresi. Teknik sampling penelitian ini adalah Stratified Random Sampling menggunakan rumus slovin. Jenis data yang digunakan dalam penelitian ini adalah data primer dan data sekunder. Hasil penelitian ini membuktikan bahwa Inovasi Produk dan Desain Produk berpengaruh positif dan signifikan terhadap Keputusan Pembelian Berulang.

Kata Kunci: Desain Produk, Inovasi Produk, Iphone Indonesia, Keputusan Pembelian Berulang

JEL Classification: M21, M31 


\section{Latar Belakang}

Dampak globalisasi yang terjadi telah membawa perubahan mendasar terhadap kehidupan manusia terutama dalam teknologi komunikasi. Perkembangan teknologi komunikasi saat ini membuat manusia semakin mudah untuk melakukan interaksi satu dengan yang lain tanpa dibatasi dengan jarak dan waktu (Musa \& Nurhaidah, 2015). Menurut Kotler \& Armstrong (2016), Inovasi produk merupakan proses pengembangan gagasan yang kreatif dan mengubahnya menjadi produk yang bermanfaat sedangkan menurut Keegan \& Green (2015), Inovasi adalah proses untuk mendapatkan sumber daya dengan kapasitas baru untuk menciptakan nilai.Banyaknya inovasi mendukung penemuan baru yang terjadi dalam industri telekomunikasi. Salah satu bukti berkembangnya teknologi komunikasi ialah semakin maraknya berbagai jenis telepon genggam yang mulai beredar di pasar. Dilihat dari masa-masa awal beredarnya telepon genggam saat ini dapat ditemukan banyak sekali perkembangan dan perubahan yang ada mulai dari segi desain, ukuran, daya simpan, kapasitas baterai dan fitur. Salah satu produk telepon genggam yang saat ini banyak diminati oleh masyarakat luas adalah smartphone. (Darian, D \& Margaretha, 2018)

Secara keseluruhan pertumbuhan akan smartphone di pasar Internasional membawa dampak yang positif bagi masyarakat karena hampir di setiap negara masyarakatnya menggunakan smartphone. Banyaknya yang menggunakan smartphone, menjadikan smartphone sebagai kebutuhan pokok masyarakat. Persaingan industri smartphone dunia yang semakin ketat mendorong para pelaku bisnis smartphone untuk lebih cerdas dan lebih berinovasi dalam membuat smartphone (Djunu, 2016). Perusahaan smartphone Asia Tenggara mulai memasuki pasar, diantaranya adalah Samsung, Iphone, Nokia, Asus, Lenovo, Oppo, Xiaomi, etc. Smartphone Cina mulai memasuki industri smartphone dunia dan bersaing dengan merek-merek smartphone lain, dengan begitu produsen smartphone dunia dituntut untuk terus berinovasi agar dapat bersaing dengan kompetitor (Augusta, 2015).

Perusahaan Riset International Gartner menerbitkan daftar penjualan smartphone di seluruh dunia menyebutkan bahwa kuartal satu sampai dengan kuartal empat di tahun 2015 sampai tahun 2019 penjualan smartphone di seluruh dunia mencapai angka lebih dari 6 miliar unit. Daftar penjualan smartphone di seluruh dunia pada tahun 2015 sampai dengan tahun 2019 disajikan pada Tabel 1.

Tabel 1. Smartphone Vendor Sales And Marketshare 2015 - 2019

\begin{tabular}{|c|c|c|c|c|c|c|c|c|c|c|}
\hline \multicolumn{11}{|c|}{ Worldwide Smartphone Sales to End Users by Vendor (Millions of Units) } \\
\hline & 2015 & 2015 & 2016 & 2016 & 2017 & 2017 & 2018 & 2018 & 2019 & 2019 \\
\hline Vendor & Units & $\begin{array}{c}\text { Market } \\
\text { Share } \\
(\%)\end{array}$ & Units & $\begin{array}{c}\text { Market } \\
\text { Share } \\
(\%)\end{array}$ & Units & $\begin{array}{c}\text { Market } \\
\text { Share } \\
(\%)\end{array}$ & Units & $\begin{array}{c}\text { Market } \\
\text { Share } \\
(\%)\end{array}$ & Units & $\begin{array}{c}\text { Market } \\
\text { Share } \\
(\%)\end{array}$ \\
\hline Samsung & $320,219.7$ & 22.5 & $306,446.6$ & 20.5 & $321,263.3$ & 20.9 & $295,043.7$ & 19.0 & $296,194.0$ & 19.2 \\
\hline Apple & $225,850.6$ & 15.9 & $216,064.0$ & 14.4 & $214,924.4$ & 14.0 & $209,048.4$ & 13.4 & $193,475.1$ & 12.6 \\
\hline Huawei & $104,094.7$ & 7.3 & $132,824.9$ & 8.9 & $150,534.3$ & 9.8 & $202,901.4$ & 13.0 & $240,615.5$ & 15.6 \\
\hline Xiaomi & $39,489.0$ & 2.8 & $85,299.5$ & 5.7 & $88,926.8$ & 5.8 & $122,387.0$ & 7.9 & $126,049.2$ & 8.2 \\
\hline OPPO & $35,291.3$ & 2.5 & $72,408.6$ & 4.8 & $112,124.0$ & 7.3 & $118,837.5$ & 7.6 & $118,693.2$ & 7.7 \\
\hline Others & $698,955.1$ & 49.1 & $682,314.3$ & 45.6 & $648,762.7$ & 42.2 & $607,049.0$ & 39.0 & $118,693.0$ & 36.7 \\
\hline Total & $1,423,900.4$ & 100.0 & $1,495,358.0$ & 100.0 & $1,536,535.5$ & 100.0 & $1,555,267.0$ & 100.0 & $1,540,657.0$ & 100.0 \\
\hline
\end{tabular}

Sumber : www.gartner.com diakses pada 27 September 2019 pukul 02.21 WIB;21 Oktober 2020 pukul 20.30

Tabel 1 menunjukan bahwa iphone tetap berada di posisi kedua dalam daftar penjualan smartphone di seluruh dunia pada tahun 2015 sampai dengan tahun 2019 meski mengalami penurunan terus-menerus. Menurut manajemen Apple, penurunan penjualan tersebut karena dua pasar terbesarnya Amerika Serikat dan China mengalami tahun terburuk untuk kinerja smartphone. Melambatnya penjualan di China dikarenakan konsumen China lebih memilih memegang iphone mereka sedikit lebih lama dari pada di masa lalu dan faktor ekonomi makro khususnya di pasar negara berkembang (https://internasional.kontan.co.id).

Permintaan akan smartphone di Indonesia mengalami peningkatan dari tahun ke tahun, hal ini ditandai akan banyaknya perusahaan-perusahaan yang menawarkan berbagai jenis smartphone. Menurut lembaga riset GFK Asia, Indonesia merupakan penyumbang terbesar dalam hal penjualan smartphone di kawasan Asia Tenggara. Peningkatan terjadi hampir 2 kali lipat dari jumlah kepemilikan handphone di Indonesia pada tahun 2019 (www.industry.co.id).

Banyak perusahaan yang menawarkan smartphone dengan berbagai spesifikasi, kualitas, desain dan merek sehingga timbulah persaingan. Menurut David (2009) berpendapat bahwa desain produk adalah 


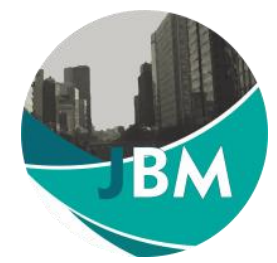

mengupayakan peningkatan penjualan melalui perbaikan produk atau pengembangan produk saat ini, sedangkan menurut Kotler dan Keller (2009) berpendapat bahwa desain produk adalah totalitas fitur yang mempengaruhi penampilan, rasa, dan fungsi produk berdasarkan kebutuhan pelanggan.Persaingan perusahaan dalam memperebutkan pangsa pasar (market share) yang sama semakin ketat. Perusahaan harus semakin pintar dalam berinovasi untuk melihat kebutuhan konsumen, karena yang dapat bertahan pada pangsa pasar yang sama adalah perusahaan yang dapat memberikan apa yang memang diinginkan konsumen (Apriliani \& Ferdinand, 2019).

Iphone adalah salah satu vendor smartphone di Indonesia. Menurut lembaga riset Statcounter Indonesia menyatakan bahwa market share iphone semakin mengalami penurunan setiap tahunnya. Pada tahun 2018, Apple menduduki posisi ke-6 dengan pangsa pasar $4.3 \%$, sedangkan pesaingnya Samsung tetap berjaya menjadi pemimpin pasar alias market leader dengan keberhasilan pangsa pasar $28.7 \%$.

Salah satu lembaga survei dalam ajang penghargaan merek terbaik pilihan Indonesia adalah Top Brand Award. Dibawah ini merupakan tabel yang menunjukkan hasil survei selama empat tahun terakhir, bahwa smartphone iphone semakin menurun atau kurang mampu bersaing dengan vendor smartphone lainnya di Indonesia

Tabel 2. Top Brand Index Kategori Smartphone 2015 - 2019

\begin{tabular}{|c|c|c|c|c|c|}
\hline Brand & 2015 & 2016 & 2017 & 2018 & 2019 \\
\hline Samsung & $43,2 \%$ & $47,3 \%$ & $38,2 \%$ & $43,5 \%$ & $46,1 \%$ \\
\hline IPhone & $13,9 \%$ & $17,4 \%$ & $15 \%$ & $13,81 \%$ & $9,6 \%$ \\
\hline Blackberry & $10,6 \%$ & & & & \\
\hline Nokia & $5,2 \%$ & & & & \\
\hline Oppo & $3,8 \%$ & $6,1 \%$ & $9,5 \%$ & $12,47 \%$ & $15 \%$ \\
\hline Sony Xperia & $3,6 \%$ & & & & \\
\hline Asus & & $6,7 \%$ & $7,1 \%$ & $2,47 \%$ & \\
\hline Lenovo & & $6,1 \%$ & $5,6 \%$ & $2,52 \%$ & \\
\hline Xiaomi & & & $7,8 \%$ & $13,05 \%$ & \\
\hline
\end{tabular}

Sumber: www.topbrand-award.com diakses pada 27 September 2019 pukul 19.20 WIB; 21 Oktober 2020 pukul 20.39

Tabel 2 menunjukan bahwa iphone terus mengalami penurunan pada index top brand hingga mencapai 9.6\% pada tahun 2019 terakhir. Sementara samsung paling unggul diantara brand lainnya, bahkan hampir setengahnya dikuasai oleh Samsung. Penjualan iphone menurun karena adanya angka penurunan upgrade dari feature iphone ke smartphone sehingga kurangnya alternative ultra-low-cost device atau perangkat murah meriah. Konsumen lebih memilih bertahan dengan smartphone model lama meskipun banyak vendor yang merilis smartphone dengan kualitas, konektivitas 4G, fitur kamera serta desain yang lebih baik.

Keputusan pembelian berulang dipengaruhi oleh persepsi inovasi produk, desain produk dan kapasitas brand (Filieri \& Lin, 2017). Sementara menurut Sukmawati dan Suyono dalam Pramono dikutip dari Annafik dan Rahardjo (2012), minat beli merupakan bagian dari komponen perilaku dalam sikap mengkonsumsi. Pada dasarnya para konsumen akan menyukai produk yang memiliki keunggulan. Inovasi produk adalah proses untuk mendapatkan sumber daya dengan kapasitas baru untuk menciptakan nilai. Menurut Kotler dan Armstrong (2008) menyatakan bahwa produk baru (inovasi produk) adalah barang, jasa, atau ide yang dianggap baru oleh sejumlah pelanggan potensial.

Perusahaan Apple melakukan inovasi produk pada 2017 yang juga menjadi momentum 10 tahun kehadiran iphone. Apple membuat gebrakan dengan meluncurkan tiga iPhone terbaru sekaligus yaitu iPhone 8 , iPhone 8 Plus, dan iPhone $X$. Iphone $X$ menjadi smatphone yang paling mencuri perhatian karena untuk pertama kalinya iPhone menggunakan layar yang nyaris tanpa bezel. Iphone $\mathrm{X}$ juga menjadi iphone pertama yang menggunakan layar OLED. Perubahan lain yang ada di iPhone $X$ yaitu dihilangkannya fitur pengenalan sidik jari bernama Touch ID, dan menggantikannya dengan fitur keamanan lain berupa sistem pengenalan wajah atau Face ID. Apple juga menghadirkan fitur menarik bernama Animoji. Apple juga melengkapi ketiga iPhone terbaru ini dengan fitur Air Power, yaitu pengisian baterai tanpa kabel.

Desain produk merupakan salah satu aspek pembentuk citra produk. Ciri pembeda produk ialah dengan sebuah desain yang unik, lain dari pada yang lain. Didukung dengan desain produk yang baik dapat meningkatkan pemasaran produk dalam berbagai hal (Tengor, Gloria; Lotje, Kawet; Loindong, 2016). 
Perusahaan apple menciptakan desain produk dengan logo yang memiliki ciri khas tersendiri sehingga mudah dikenali oleh masyarakat. Iphone juga memiliki desain produk yang mewah dan elegan dengan berbagai pilihan warna yang menarik.

\section{Metode Penelitian}

Ruang lingkup Penelitian dalam penelitian ini yaitu menganalisis bagaimana pengaruh inovasi produk dan desain produk terhadap keputusan pembelian berulang smartphone iphone. Objek penelitian yang menjadi variabel bebas pada penelitian ini yaitu inovasi produk (X1) dan desain produk (X2), kemudian variabel terikat yaitu keputusan pembelian berulang $(Y)$. Penelitian ini dilaksanakan pada komunitas iphone Indonesia dan forum iphone indonesia. Populasi dalam penelitian ini adalah anggota komunitas iphone yang ada di Indonesia.

Tabel 3. Jumlah Anggota Komunitas Smartphone Iphone

\begin{tabular}{llr}
\hline \multicolumn{2}{c}{ Jumlah Anggota Komunitas Smartphone Iphone } \\
\hline 1. & Komunitas Iphone Indonesia & 66.701 orang \\
2. & Komunitas Apple Indonesia & 4100 orang \\
3. & Komunitas Pengguna Iphone Indonesia & 111 orang \\
4. & Komunitas Iphone & 1200 orang \\
5. & Komunitas Pecinta Iphone & 2100 orang \\
6. & Forum Iphone Indonesia & 177.000 orang \\
& Jumlah & $\mathbf{2 5 1 , 2 1 2}$ orang \\
\hline
\end{tabular}

Sumber: Fanpage Komunitas Smartphone Iphone, 2019

Sampel akan diambil dari target populasi melalui pengisian kuesioner. Jumlah sampel yang ditetapkan adalah 100 orang yang memenuhi kriteria target populasi. Analisis data merupakan kegiatan pengolahan data yang telah terkumpul untuk menjawab rumusan masalah dan menguji hipotesis yang telah diajukan. Teknik analisis data yang digunakan dalam penelitian ini adalah regresi linier berganda.

\section{Hasil Peneltian}

Sebelum melakukan uji regresi linier berganda, maka peneliti melakukan uji asumsi klasik sebagai pra syarat dilakukannya uji regresi linier berganda. Uji normalitas pada penelitian ini ditemukan bahwa nilai Asymp. Sig. (2tailed) lebih dari 0,05 pada masing-masing variabel. Maka dapat disimpulkan bahwa data penelitian berdistribusi normal. Uji heteroskedatisitas dapat dilakukan dengan uji glesjer dengan membandingkan nilai signifikansi dengan 0,05 . Berdasarkan data yang telah diolah dapat dilihat bahwa nilai sig dari Inovasi Produk lebih besar dari 0,05 dan dari Design Produk lebih besar dari 0,05. Sehingga dapat dikesimpulkan bahwa data penelitian tidak mengalami masalah heteroskedatisitas. Selanjutnya adalah uji multikolinieritas dengan untuk menguji ada tidaknya hubungan antara variabel bebas. Hasil uji multikolinieritas menunjukkan bahwa nilai VIF pada kedua variabel bernilai 2,117 yang berarti bahwa tidak ada masalah multikolinieritas di dalam penelitian ini. Dengan demikian, keseluruhan uji asumsi klasik menunjukkan tidak ada permasalahan sehingga dapat dilanjutkan untuk uji regresi linier berganda.

Analisis regresi digunakan untuk mengetahui nilai koefiesien variabel penelitian. Selain itu, uji regresi dapat juga digunakan sebagai uji hipotesis pada penelitian ini. Berikut adalah hasil dari uji regresi linier berganda pada penelitian ini.

\section{Tabel 4. Coefficients}

\begin{tabular}{|c|c|c|c|c|c|c|}
\hline \multirow{2}{*}{ Model } & & \multicolumn{2}{|c|}{$\begin{array}{l}\text { Unstandardized } \\
\text { Coefficients }\end{array}$} & \multirow{2}{*}{$\begin{array}{c}\text { Standardized } \\
\text { Coefficients } \\
\text { Beta }\end{array}$} & \multirow{2}{*}{$\mathrm{T}$} & \multirow{2}{*}{ Sig. } \\
\hline & & B & $\begin{array}{l}\text { Std. } \\
\text { Error }\end{array}$ & & & \\
\hline \multirow{3}{*}{1} & (Constant) & 0,459 & 2,609 & & 0,176 & 0,861 \\
\hline & Inovasi & 0,355 & 0,084 & 0,441 & 4,219 & 0,000 \\
\hline & Desain & 0,213 & 0,07 & 0,318 & 3.042 & 0,003 \\
\hline
\end{tabular}

Sumber : Data diolah (2021)

Berdasarkan tabel tersebut maka diperoleh persamaan regresi sebagai berikut:

$$
Y=0,459+0,355 X 1+0,213 X 2+e
$$

Dimana, 


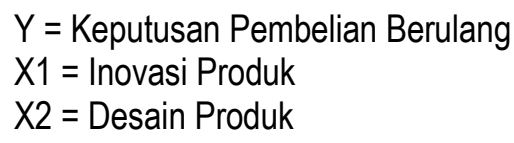

Berdasarkan hasil uji regresi linier berganda, dapat diketahui bahwa nilai koefisien dari masing-masing variabel menunjukkan nilai positif yang berarti bahwa inovasi dan desain produk memiliki pengaruh positif terhadap keputusan pembelian berulang. Selanjutnya, t-hitung dari masing-masing variabel dependen lebih besar dari t-tabel yang bernilai 1,66 sehingga dapat dikatakan terdapat pengaruh signifikan dari inovasi produk dan desain produk terhadap keputusan pembelian berulang.

Dilakukan juga Uji $F$ untuk mengetahui pengaruh variabel bebas secara simultan terhadap variabel terikat. Uji $F$ dapat juga digunakan untuk menguji kelayakan model yang digunakan di dalam sebuah penelitian. Berikut adalah hasil Uji F pada penelitian ini.

Tabel 5. ANOVA

\begin{tabular}{|c|c|c|c|c|c|c|}
\hline \multicolumn{2}{|l|}{ Model } & Sum of Squares & df & Mean Square & $\mathrm{F}$ & Sig. \\
\hline \multirow[t]{3}{*}{1} & Regression & 554,806 & 2 & 277,403 & 48,380 & $0,000^{a}$ \\
\hline & Residual & 556,184 & 97 & 5,734 & & \\
\hline & Total & 1110,990 & 99 & & & \\
\hline
\end{tabular}

Sumber: Data diolah (2021)

Dapat diketahui bahwa nilai f-hitung dari lebih besar dari f-tabel yang bernilai 3,91 sehingga dapat disimpulkan bahwa inovasi produk dan desain produk secara simultan berpengaruh signifikan terhadap keputuan pembelian berulang. Selain itu, berdasarkan hasil Uji $\mathrm{F}$ dapat juga disimpulkan bahwa model penelitian yang diajukan di dalam penelitian ini adalah layak.

Selanjutnya, peneliti melakukan uji koefisien determinasi untuk mengetahui tingkat pengaruh variabel bebas terhadap variabel terikat. Berikut adalah hasil dari uji koefisien determinasi pada penelitian ini.

Tabel 6. Model Summary

\begin{tabular}{lllll} 
Model & $\mathbf{R}$ & R-Square & $\begin{array}{c}\text { Adjusted } \mathbf{R} \\
\text { Square }\end{array}$ & $\begin{array}{c}\text { Std. Error of the } \\
\text { Estimate }\end{array}$ \\
\hline 1 & $0,707^{a}$ & 0,499 & 0,489 & 2,395 \\
\hline Sumber: Data diolah (2021) & & &
\end{tabular}

Nilai tingkat pengaruh variabel bebas dapat dilihat pada nilai R-square. Pada hasil penelitian ini diketahui bahwa nilai R-square sebesar 0,499, maka dapat diartikan bahwa tingkat pengaruh inovasi produk dan desain produk terhadap keputusan pembelian berulang sebesar 49,9\%. Berdasarkan hasil tersebut dapat disimpulkan juga bahwa $50,1 \%$ yang mempengaruhi keputusan pembelian dipengaruhi oleh variabel lain yang tidak diteliti pada penelitian ini.

\section{Pembahasan}

\section{Pengaruh Inovasi Produk terhadap Keputusan Pembelian Berulang}

Hasil pengujian yang dilakukan berdasarkan nilai thitung didapatkan sebesar 4,219 lebih besar dibandingkan dengan nilai ttabel yang sebesar 1,66 sehingga dapat dikesimpulkan bahwa inovasi produk memiliki pengaruh positif dan signifikan terhadap keputusan pembelian berulang. Hal ini sesuai dengan hasil penelitian yang dilakukan oleh Andri, dkk (2018) yang menyatakan bahwa terdapat pengaruh antara inovasi produk dengan keputusan pembelian berulang. Dimana dengan inovasi suatu produk dapat menjadi pertimbangan dalam melakukan keputusan pembelian berulang. Hal ini juga berkesesuaian dengan pandangan Kotler dan Amstrong (2008) yang berpendapat bahwa dengan adanya sebuah inovasi dalam sebuah produk baru menarik konsumen untuk mencobanya untuk pertama kalinya untuk dipelajari dan membuat suatu keputusan pembelian berulang. 


\section{Pengaruh Desain Produk terhadap Keputusan Pembelian Berulang}

Hasil pengujian yang dilakukan berdasarkan nilai thitung didapatkan sebesar 3,042 lebih besar dibandingkan dengan nilai ttabel yang sebesar 1,66 sehingga dapat dikesimpulkan bahwa desain produk memiliki pengaruh positif dan signifikan terhadap keputusan pembelian berulang. Hal ini sesuai dengan hasil penelitian yang dilakukan oleh Gloria Tenggor et.al (2016) yang menyatakan bahwa terdapat pengaruh antara desain produk secara pasial terhadap keputusan pembelian berulang. Hal tersebut, dikarenakan dalam proses keputusan pembelian berulang didasarkan oleh pemberian peringkat atribut produk yang salah satunya ialah desain produk.Maka dari itu perusahaan akan membuat desain produk yang semenarik mungkin agar berbeda dan memiliki ciri khas sehingga membedakan dengan produk lainnya. Iphone juga menawarkan desain produk yang lebih upto date dalam stylenya dan kejernihan suara yang ditawarkan.

\section{Pengaruh Inovasi Produk dan Desain Produk terhadap Keputusan Pembelian Berulang}

Hasil penelitian ini banyak didukung oleh penelitian-penelitian sebelumnya. Seperti pada penelitian penelitian Tengor, Gloria; Lotje, Kawet; Loindong, Sjendry (2016) menunjukkan bahwa hasil analisis statistik ternyata merek, desain produk, dan kualitas produk secara bersama- sama berpengaruh terhadap keputusan pembelian Iphone. Dengan melihat nilai Fhitung $(43,83)$ lebih besar dari Ftabel $(3,91)$ maka dapat dikesimpulkan bahwa inovasi produk dan desain produk berpengaruh secara simultan terhadap keputusan pembelian Iphone. Serta didukung penelitian yang dilakukan oleh Budiyanto (2005) yang menyatakan jika perusahaan melakukan inovasi produk secara berkelanjutan disertai dengan desain produk yang menarik akan menjadi pertimbangan dalam keputusan pembelian secara berulang.

\section{Kesimpulan}

Berdasarkan hasil penelitian yang telah dilakukan menggunakan analisis deskriptif dan verifikatif maka dapat diambil kesimpulan bahwa inovasi dan desain produk memiliki pengaruh positif dan signifikan inovasi produk terhadap keputusan pembelian berulang baik secara parsial maupun simultan. Hal tersebut berarti bahwa salah s penyebab customer setia memilih brand i-phone di dasarkan pada dua hal tersebut.

\section{DAFTAR PUSTAKA}

Abdullah, C. (2018). BAB III. Nucleic Acids Research, 57-77.

Andri Tri Setiawan, Achmad Fauzi DH, and Brillyanes Sanawiri. 2018. "PENGARUH GAYA HIDUP DAN INOVASI PRODUK TERHADAP KEPUTUSAN PEMBELIAN( Survei Pada Mahasiswa S1 Jurusan IImu Administrasi Bisnis Angkatan 2014 / 2015 Fakultas Ilmu Administrasi Universitas Brawijaya Malang Yang Membeli , Menggunakan Dan Mengetahui Smartphon." 62(1): 73-81.

Al rasyid, H., \& Tri Indah, A. (2015). Pengaruh Inovasi Produk, Harga Dan Brand Image Terhadap Keputusan Pembelian Sepeda Motor Honda Beat. Perspektif, 16(1), 39-49.

Apriliani, L., \& Ferdinand, A. T. (2019). FAKTOR - FAKTOR YANG MEMPENGARUHI KEUNGGULAN BERSAING DALAM UPAYA MENINGKATKAN MARKET SHARE. Journal of Chemical Information and Modeling, 53(9), 1689-1699. https://doi.org/10.1017/CBO9781107415324.004

Augusta, G. (2015). Pengaruh penggunaan smartphone terhadap prestasi belajar mahasiswa melalui motivasi belajar.

Bruce, 2011. (2013). 済無No Title No Title. Journal of Chemical Information and Modeling, 53(9), 1689-1699. https://doi.org/10.1017/CB09781107415324.004

Darian, D \& Margaretha, P. (2018). Analisis Pengaruh Kualitas Produk dan Inovasi Produk Terhadap Keputusan Pembelian Smartphone. Jurnal Manajemen Ekonomi, 138, 138.

Djunu, A. (2016). PEMANFAATAN FITUR INTERNET PADA SMARTPHONE OLEH MASYARAKAT (Studi Pada Ibu-lbu Rumah Tangga Kelurahan Tidore Kecamatan Tahuna Timur). Jurnal Acta Diurna, V(5), 1-15.

Filieri, R., \& Lin, Z. (2017). The role of aesthetic, cultural, utilitarian and branding factors in young Chinese consumers' repurchase intention of smartphone brands. Computers in Human Behavior, 67, 139-150. https://doi.org/10.1016/j.chb.2016.09.057

goleman, daniel; boyatzis, Richard; Mckee, A. (2019). 済無No Title No Title. Journal of Chemical Information 
and Modeling, 53(9), 1689-1699. https://doi.org/10.1017/CBO9781107415324.004

Hellier, P. K., Geursen, G. M., Carr, R. A., \& Rickard, J. A. (2018). Customer repurchase intention. In European Journal of Marketing (Vol. 37). https://doi.org/10.1108/03090560310495456

li, B. A. B., Teori, A. L., \& Ulang, N. B. (2008). Bab ii. 14-46.

Luchs, M. G., Swan, K. S., \& Creusen, M. E. H. (2016). Perspective: A Review of Marketing Research on Product Design with Directions for Future Research. Journal of Product Innovation Management, 33(3), 320-341. https://doi.org/10.1111/jpim.12276

Musa, M. I., \& Nurhaidah. (2015). pembaharuan dalam pemanfaatan hasil-hasil teknologi. 3(3), 1-14.

Pengabdian, J., \& Masyarakat, K. (2017). 1) , 2) , ) 2. 1(1), 31-39.

Tengor, Gloria; Lotje, Kawet; Loindong, S. (2016). Pengaruh Merek, Desain Dan Kualitas Produk Tehadap Keputusan Pembelian Iphone Studi Kasus Pada Mahasiswa STIE Eben Haezer Manado. Jurnal Berkala IImiah Efisiensi, 16(4), 369.

www.industry.co.id

Wulan, A. (2010). BAB II Tinjauan Pustaka Anemia. Universitas Muhammadiyah Surakarta, 5-18. 